\begin{tabular}{|c|c|}
\hline $\begin{array}{l}\text { Chemistry of } \\
\text { Metals and Alloys }\end{array}$ & $\begin{array}{l}\text { Chem. Met. Alloys } 4 \text { (2011) 67-71 } \\
\text { Ivan Franko National nuviersity of LViv } \\
\text { www.chemetal-journal.org }\end{array}$ \\
\hline
\end{tabular}

\title{
Nano- and micro-size $\mathrm{V}_{2} \mathrm{O}_{5}$ structures
}

\author{
V.N. SHEVCHUK ${ }^{1 *}$, Yu.N. USATENKO ${ }^{2}$, P.Yu. DEMCHENKO ${ }^{3}$, O.T. ANTONYAK ${ }^{4}$, R.Ya. SERKIZ ${ }^{2}$ \\ ${ }^{1}$ Faculty of Electronics, Ivan Franko National University of Lviv, Dragomanova St. 50, 79005 Lviv, Ukraine \\ ${ }^{2}$ Scientific-Technical and Educational Center of Low-Temperature Studies, Ivan Franko National University \\ of Lviv, Dragomanova St. 50, 79005 Lviv, Ukraine \\ ${ }^{3}$ Department of Inorganic Chemistry, Ivan Franko National University of Lviv, \\ Kyryla i Mefodiya St. 6, 79005 Lviv, Ukraine \\ ${ }^{4}$ Faculty of Physics, Ivan Franko National University of Lviv, Kyryla i Mefodiya St. 8, 79005 Lviv, Ukraine \\ *Corresponding author.Tel.: +380-32-394326; e-mail: shevchuk@electronics.wups.lviv.ua
}

Received July 6, 2010; accepted May 18, 2011; available on-line November 8, 2011

A simple closed-volume technique similar to the Bridgman method was used to obtain $\mathrm{V}_{2} \mathrm{O}_{5}$ micro- and nanocrystalline structures. The morphological features of the produced crystalline structures were investigated by scanning electron microscopy and $\mathrm{X}$-ray diffraction. Some of the observed $\mathrm{V}_{2} \mathrm{O}_{5}$ structures are briefly described taking into account physicochemical conditions of the preparation.

\section{$\mathrm{V}_{2} \mathrm{O}_{5}$ / Nano-crystalline structures / X-ray diffraction}

\section{Introduction}

Vanadium oxides are typical polyfunctional materials and have attracted strong interest over the past years for their electrical, optical, electrochemical properties: metal-to-insulator transitions, electrical switching of $\mathrm{V}_{2} \mathrm{O}_{5}$, high ion interaction capacity, high sensitivity of active elements for gas sensors, etc. [1-6]. Vanadium pentoxide in different forms has been intensively studied. Nano-structured $\mathrm{V}_{2} \mathrm{O}_{5}$ is a unique material with properties depending on the conditions of preparation.

Vanadium pentoxide nanorods and nanowires have been synthesized by the reverse micelle technique [2]. The length, from $40 \mathrm{~nm}$ to $1 \mu \mathrm{m}$, can easily be tuned by keeping the particles in a micellar solution after the synthesis. Cao et al. [3] describe a simple method to self-assemble $\mathrm{V}_{2} \mathrm{O}_{5}$ nanorods into microspheres. A synthesis of vanadium pentoxide nanorods based on thermal decomposition of vanadium chloride vapor is proposed in [4]. Micro- and nanorods with thicknesses in the range from $50 \mathrm{~nm}$ to $5 \mu \mathrm{m}$ and lengths of up to $7 \mu \mathrm{m}$ were obtained. $\mathrm{V}_{2} \mathrm{O}_{5}$ compacted nanopowder was used by Diaz-Guerra and Piqueras [5] and nanorods and nanotips with a thickness in the range from $50 \mathrm{~nm}$ to $100 \mathrm{~nm}$ on the top of rods of larger size were obtained in this case.

In this work, using $\mathrm{V}_{2} \mathrm{O}_{5}$ powder $\mathrm{V}_{2} \mathrm{O}_{5}$ crystals and elongated micro- and nanostructures with the short dimensions in the range from $0.1 \mu \mathrm{m}$ to $0.5 \mu \mathrm{m}$ were obtained. The length varied from $20 \mu \mathrm{m}$ to $150 \mu \mathrm{m}$. The investigated nano- and micro-size crystalline structures were obtained in a closed volume (ampoule) using a growing technique based on the Bridgman method. Images of the synthesized $\mathrm{V}_{2} \mathrm{O}_{5}$ structures were obtained by a scanning electron microscope (SEM). The phase compositions of the micro- and nano-structures were controlled by $\mathrm{X}$-ray diffraction (XRD).

Part of our experimental data on the growth of nano- and micro-size $\mathrm{V}_{2} \mathrm{O}_{5}$ crystalline elongated structures were reported in [7].

\section{Experimental}

Vanadium oxides have been extensively studied because of their important properties. The $\mathrm{V}_{2} \mathrm{O}_{5}$ compound has an orthorhombic structure with lattice parameters $a=3.563 \AA, b=11.510 \AA, c=4.369 \AA$ [8]. The building block is a deformed $\mathrm{VO}_{6}$ octahedron. The shortest $\mathrm{V}-\mathrm{O}$ bond length corresponds to a double vanadyl bond $\left(\mathrm{V}-\mathrm{O}_{1}=1.585 \AA\right)$. The other oxygens, labelled $\mathrm{O}_{2}$ and $\mathrm{O}_{3}$, are bonded to two and three vanadium atoms, respectively. The longest $\mathrm{V}-\mathrm{O}$ bond $\left(\mathrm{V}-\mathrm{O}_{1}=2.785 \AA\right.$ ) is a weak van der Waals bond. $\mathrm{V}_{2} \mathrm{O}_{5}$ has a layered structure with an easy cleavage plane (perpendicular to the $c$-axis).

Vanadium pentoxide has a relatively low melting point (963 K [9]) and crystals can easily be obtained from the melt. During the growing process based on the Bridgman technique [10] used in this work we obtained $\mathrm{V}_{2} \mathrm{O}_{5}$ crystals (Fig. 1) and different structures with micro- and nano-dimensions. The crystal growth 
Table 1 Parameters from the Rietveld structure refinement of different $\mathrm{V}_{2} \mathrm{O}_{5}$ samples (unit cell parameters $a$, $b$, and $c(\AA)$; reliability factors $R_{p}, R_{w p}$, and $R_{B}(\%)$; average size $\langle d\rangle$ of the coherent scattering domain $(\AA)$, and average maximal stress $\langle\varepsilon\rangle(\%)$; preferred orientation $D$ and orientation parameter $\delta$ : starting powder $(I)$, sample prepared from original starting powder $(I I)$; sample prepared from thermally treated starting powder (III).

\begin{tabular}{l|c|l|l|c|c|c}
\hline & $a$ & $b$ & $c$ & $R_{p} ; R_{w p} ; R_{B}$ & $\langle d\rangle ;\langle\varepsilon\rangle$ & $D ; \delta$ \\
\hline$I$ & $3.56403(8)$ & $11.5097(3)$ & $4.37164(14)$ & $3.35 ; 4.22 ; 5.99$ & $805 \pm 36$ & {$[110]$} \\
& & & & & $14.6( \pm 6.5) \times 10^{-4}$ & $-0.180(9)$ \\
$I I$ & $3.56606(2)$ & $11.51465(10)$ & $4.37678(19)$ & $1.97 ; 2.54 ; 4.50$ & $875 \pm 209$ & {$[001],[110]$} \\
& & & & & $12.9( \pm 2.7) \times 10^{-4}$ & $2.52(5), 0.575(8)$ \\
$I I I$ & $3.56542(3)$ & $11.51230(10)$ & $4.3777(2)$ & $2.56 ; 3.21 ; 3.57$ & $907 \pm 211$ & {$[001],[110]$} \\
& & & & & $12.5( \pm 2.7) \times 10^{-4}$ & $2.26(5), 0.73(2)$ \\
\hline
\end{tabular}

Table 2 Positional $(x, y, z)$ and displacement parameters $\left(B_{i s o}\right)$ of the atoms in the structure of $\mathrm{V}_{2} \mathrm{O}_{5}($ sample III in Table 1).

\begin{tabular}{l|c|c|c|c|c}
\hline Atom & $\begin{array}{c}\text { Wyckoff } \\
\text { position }\end{array}$ & $x$ & $y$ & $z$ & $B_{\text {iso }}\left(\AA^{2}\right)$ \\
\hline $\mathrm{V}$ & $4 e$ & $1 / 4$ & $0.0963(3)$ & $0.399(1)$ & $0.84(8)$ \\
$\mathrm{O}_{1}$ & $4 e$ & $1 / 4$ & $0.118(1)$ & $0.068(5)$ & $0.6(3)$ \\
$\mathrm{O}_{2}$ & $4 e$ & $1 / 4$ & $0.5694(5)$ & $0.536(3)$ & $2.9(2)$ \\
$\mathrm{O}_{3}$ & $2 a$ & $1 / 4$ & $1 / 4$ & $0.522(5)$ & $0.7(2)$ \\
\hline
\end{tabular}

was realized in evacuated quartz ampoules. The vertical displacement speed was set at about $6 \mathrm{~mm} / \mathrm{h}$. The temperature of the active zone was higher than the melting temperature by $30 \mathrm{~K}$. The crystallized parts were cooled to room temperature at the switch-off regime of the furnace.

Stoichiometric $\mathrm{V}_{2} \mathrm{O}_{5}$ (purity $>98.5 \%$ ) was used as starting material for the crystal growth. The impurity contents of the original powder were in the range 0.01-0.30 mass \%. In particular, the average content of Si-compounds was 0.24 mass\%. Purification of the starting material was carried out by the horizontal zone melting method (thermally treated starting powder). For a comparison with the standard case (free from special additions), we added up to 10 mass\% of highly dispersed $\mathrm{SiO}_{2}$ to the starting material of some samples.

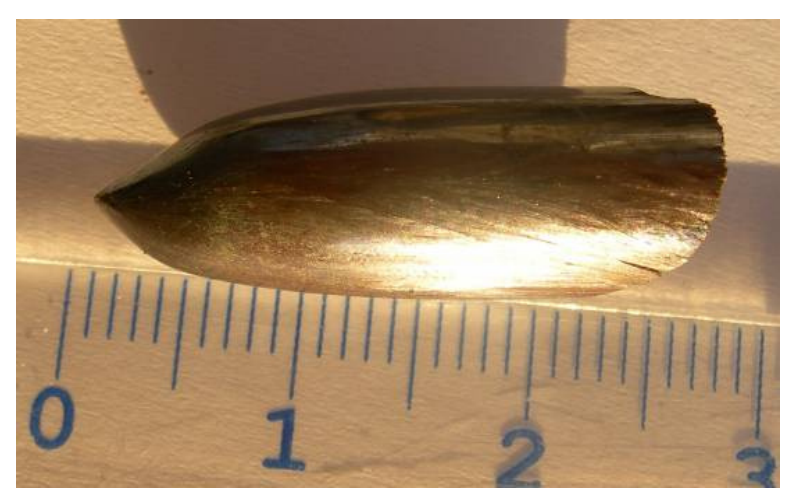

Fig. 1 Photograph of a $\mathrm{V}_{2} \mathrm{O}_{5}$ crystal obtained by the Bridgman method.
The surface morphology of the samples was studied and X-ray microanalysis carried out using a REMMA-102-02 type scanning electron microscope. The XRD analysis was performed on a STOE STADI P powder diffraction system. Arrays of experimental intensities and diffraction angles were obtained using the above mentioned diffractometer equipped with a linear position sensitive detector PSD in a modified Guinier geometry scheme in BraggBrentano transmission mode. Conditions of the measurements: monochromatic $\mathrm{Cu} \mathrm{K} \alpha_{1}$ radiation $(\lambda=1.540598 \AA)$; bent Johann type [111] Gemonochromator; $\omega / 2 \theta$-scan; $2 \theta$-range $4^{\circ} \leq 2 \theta \leq 120^{\circ}$; step $0.480^{\circ}(2 \theta)$; step scan time $250 \mathrm{~s}$. The other XRD-measurement details were the same as described previously [11]. The investigations were carried out at room temperature.

\section{Results and discussion}

A $\mathrm{V}_{2} \mathrm{O}_{5}$ crystal boule is shown in Fig. 1. The crystals are brown or yellow-brown, and cleave into layers. Macrodefects (micropore channel) are occasionally observed in the crystal bulk. XRD patterns of the starting material and the grown crystal are shown in Fig. 2. As seen from the XRD-analysis, the obtained crystal is single-phase. The crystal structure of vanadium pentoxide $\mathrm{V}_{2} \mathrm{O}_{5}$ belongs to the orthorhombic $\mathrm{V}_{2} \mathrm{O}_{5}$ structure type, space group Pmmn. The crystallographic characteristics and microstructural parameters of the investigated crystals are given in Table 1 . The atom coordinates and isotropic displacement parameters of the structure are 


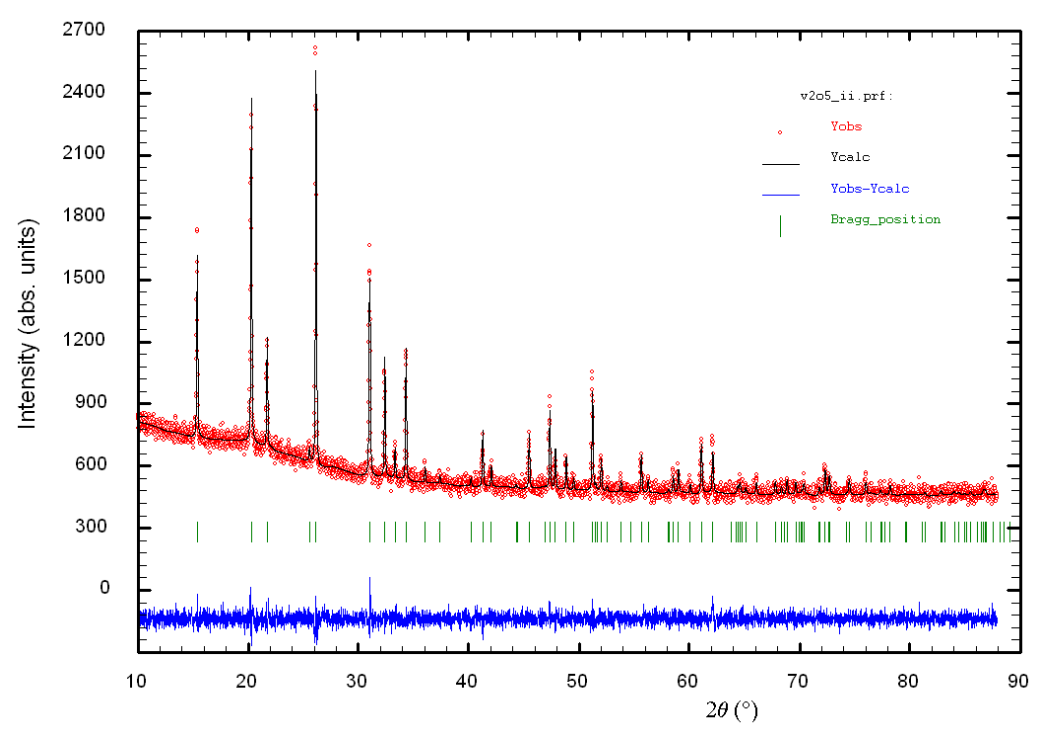

$\mathrm{a}$

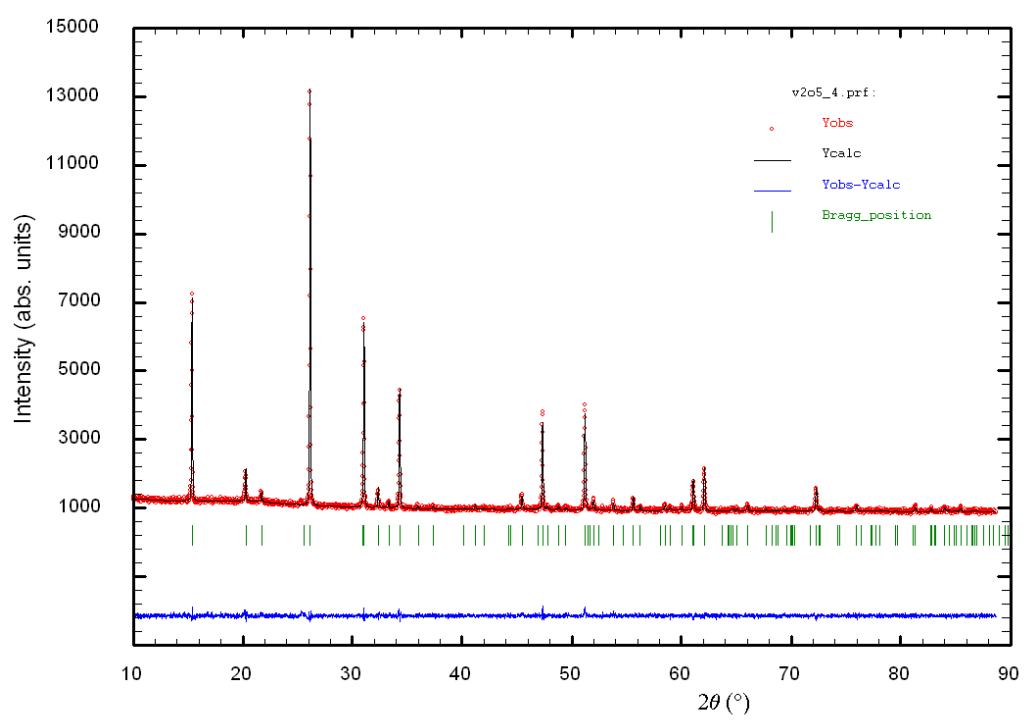

b

Fig. 2 Typical $\mathrm{X}$-ray diffraction patterns of the $\mathrm{V}_{2} \mathrm{O}_{5}$ starting material (a) and an as-grown $\mathrm{V}_{2} \mathrm{O}_{5}$ nominally pure crystal (b) at $295 \mathrm{~K}$.

presented in Table 2. The surface of samples II and III was strongly textured (dominating orientations of the atom planes) with preferred orientation along the [001] and [110] directions. The obtained data confirm the dependence of the XRD-parameters on the preliminary thermal treatment of the starting material. The differences are most likely caused by vacancy defects in the oxygen sublattice.

The SEM analysis (Fig. 3) of the $\mathrm{V}_{2} \mathrm{O}_{5}$ crystal shows the real layer-like structure. The resolution is about $200 \mathrm{~nm}$. Fig. 4 shows the results of the X-ray microanalysis. In the crystals without addition of $\mathrm{SiO}_{2}$ (Fig. 4a) only small amounts of Si were detected in addition to the basic elements of vanadium oxide $-\mathrm{V}$ and $\mathrm{O}$. The aggregates of small spheres (diameter about $2-4 \mu \mathrm{m}$ ) shown in the inset of Fig. $4 \mathrm{~b}$ are the $\mathrm{SiO}_{2}$ phase.

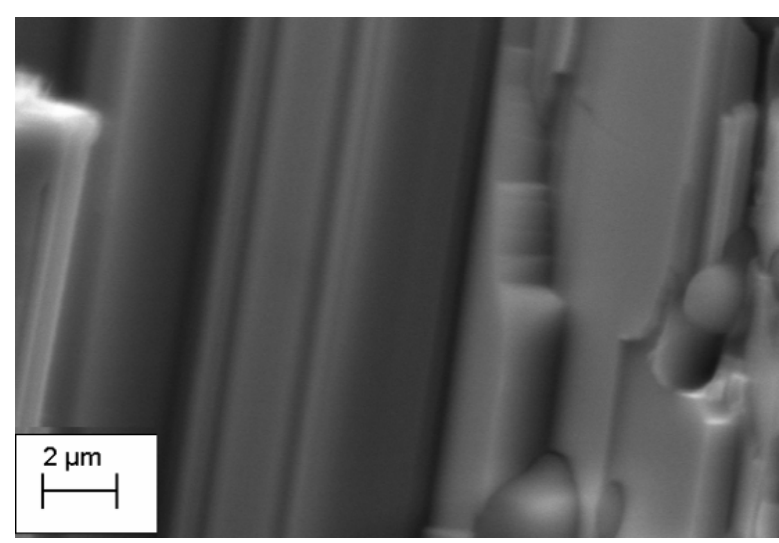

Fig. 3 SEM-image of $\mathrm{V}_{2} \mathrm{O}_{5}$ crystalline layers. 
a)

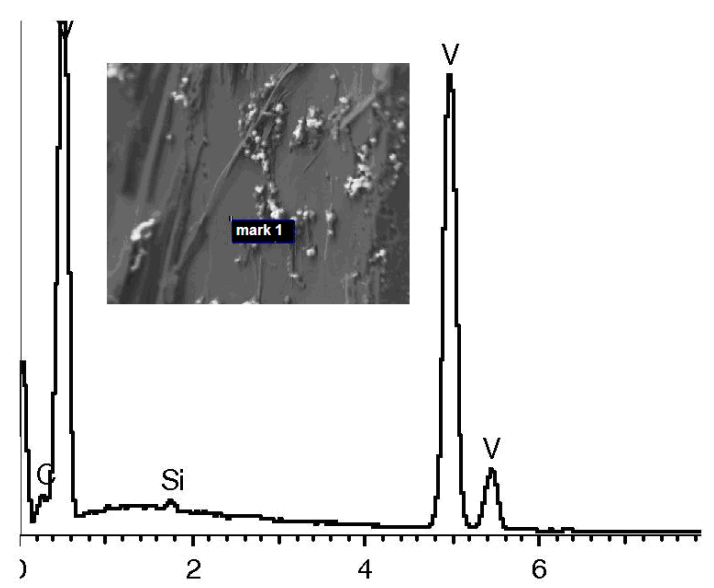

b)

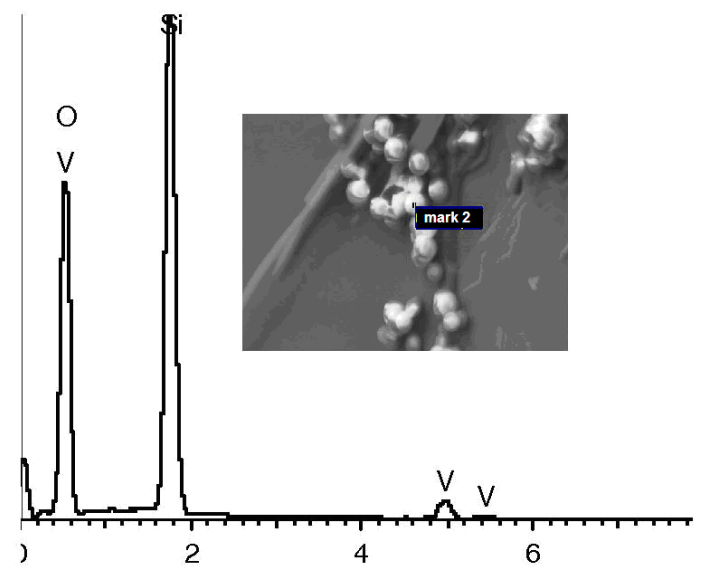

Fig. 4 X-ray microanalysis performed on a nominally pure $\mathrm{V}_{2} \mathrm{O}_{5}$ sample (a) and for $\mathrm{V}_{2} \mathrm{O}_{5}$ with $\mathrm{SiO}_{2}$ precipitates (b).

a)

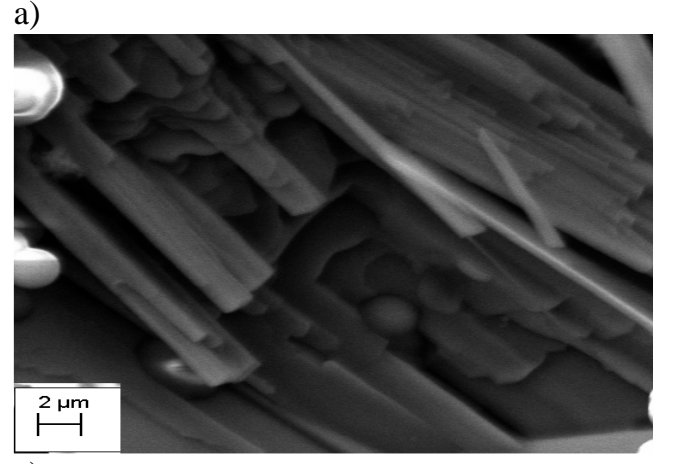

c)

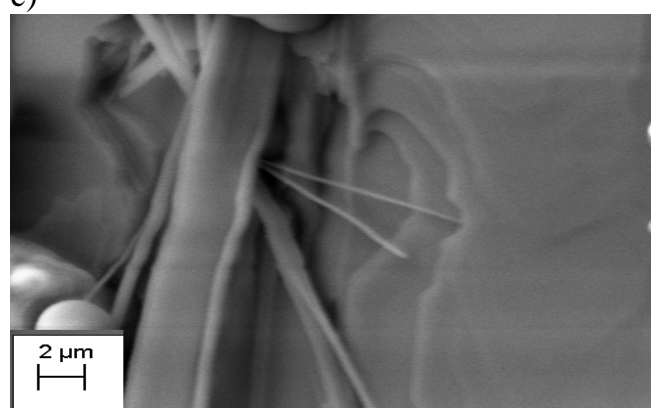

e)

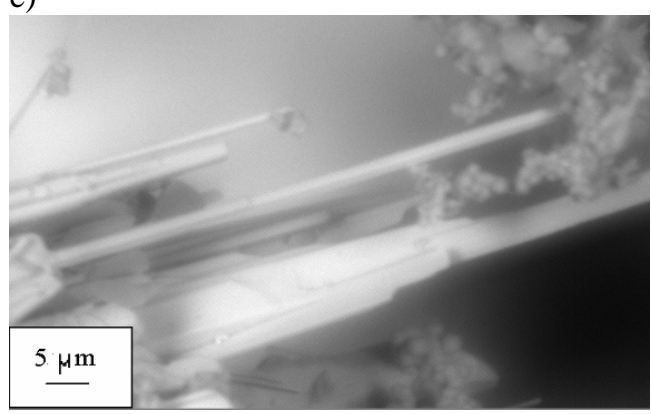

b)
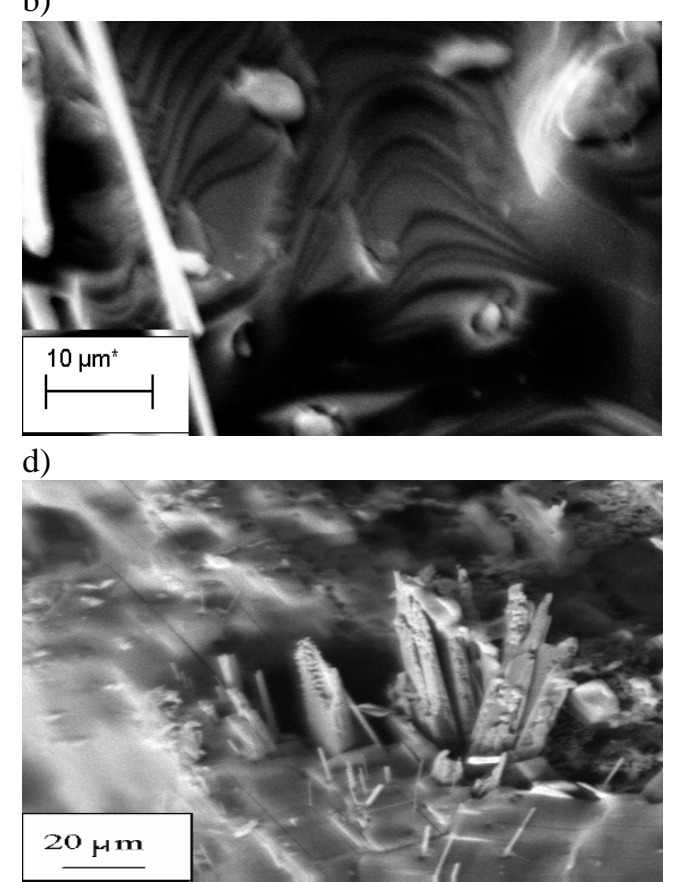

f)

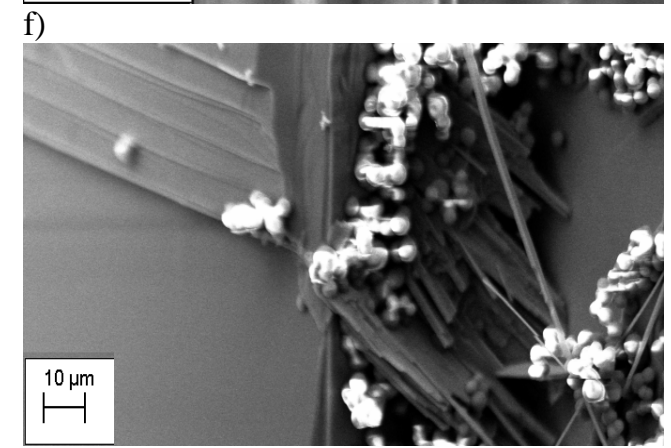

Fig. 5 SEM-images of typical $\mathrm{V}_{2} \mathrm{O}_{5}$ crystalline structures: lamellar microcrystals (a); terraced surface and elongated, rod-shaped structures (b, c); needle-like and elongated structures (d); rods and stairs-like structures (e, f). 
Figs. 5(a-f) show typical basic micro- and nanostructures observed in the samples. It is significant that in undoped $\mathrm{V}_{2} \mathrm{O}_{5}$ samples, crystalline micro- and nanostructures are practically not observed. In the composite $\mathrm{V}_{2} \mathrm{O}_{5} / \mathrm{SiO}_{2}$ the presence of $\mathrm{SiO}_{2}$ together with the layered nature of the $\mathrm{V}_{2} \mathrm{O}_{5}$ structure has caused the formation of crystalline nanoand microstructures (Fig. 5).

Our synthesized nano- and micro-size crystalline structures $(0.1-0.5 \mu \mathrm{m}$ minimal and 20-150 $\mu \mathrm{m}$ maximal dimensions), are similar to those described in the literature (see e.g. [2-5,12-14]), even if the synthesis was realized by a different method. In this work the formation of rod-shaped crystals, whiskers, and also lamellar crystals and planar ordered textures consisting of oriented rodious vanadium oxides is exposed. Terraced surfaces and stairs-like structures were occasionally observed (see Fig. 5). Planar structures with one developed surface are also formed, the surface being probably parallel to the (001) plane.

Evidently, the layered structure of vanadium pentoxide with well-defined spacing between the V-O layers plays a leading role in the formation of nanostructures. The introduction of $\mathrm{SiO}_{2}$ nanopowder as a template provided an additional condition for the formation of nanostructured $\mathrm{V}_{2} \mathrm{O}_{5}$. Growing of microcrystals is realized in the region of the micropores and also on the surface of the $\mathrm{SiO}_{2}$ particles and on exposed surfaces of crystalline $\mathrm{V}_{2} \mathrm{O}_{5}$.

\section{Conclusion}

The proposed procedure provides a possibility to obtain nano- and micro-size $\mathrm{V}_{2} \mathrm{O}_{5}$ crystalline structures of different morphologies. Changes of the physicotechnical conditions of the synthesis causes modifications of the morphology and dimensions of the nanostructures.

\section{References}

[1] D.C. Yin, M. Wang, W.D. Huang, J. Mater. Sci. Lett. 18 (1999) 1239-1241.

[2] N. Pinna, M. Willinger, K. Weiss, J. Urban, R. Schlögl, Nano Lett. 3 (2003) 1131-1134.

[3] A.-M. Cao, J.-S. Hu, H.-P. Liang, L.-J. Wan, Angew. Chem., Int. Ed. 44 (2005) 4391-4395.

[4] A.I. Sidorov, O.P. Vinogradov, V.Yu. Lyubimov, A.V. Nashchekin, Pis'ma Zh. Eksp. Teor. Fiz. 34(3) (2008) 90-94.

[5] C. Diaz-Guerra, J. Piqueras, Cryst. Growth Des. 8 (2008) 1031-1034.

[6] I. Raible, M. Burghard, U. Schlecht, A. Yasuda, T. Vossmeyer, Sens. Actuators, B 105 (2005) 730-735.

[7] V.N. Shevchuk, Yu.N. Usatenko, P.Yu. Demchenko, O.T. Antonyak, R.Ya. Serkiz, Abstr. 8th Int. Conf. Electron. Processes Org. Inorg. Mater. (ICEPOM-8), Ivano-Frankivs'k, Ukraine, 2010, pp. 145-146.

[8] L. Fiermans, P. Clauws, W. Lambrecht, L. Vandenbroucke, J. Vennik, Phys. Status Solidi A 59(2) (1980) 485-504.

[9] G.W. Kaye, T.H. Laby, Tables of Physical and Chemical Constants, Longmans, Green \& Co, London-New York-Toronto, 1958.

[10] H.E. Buckley, Crystal Growth, New York: Wiley; London: Chapman \& Hall, 1951.

[11] V.N. Shevchuk, D.I. Popovych, Yu.N. Usatenko, P.Yu. Demchenko, R.Ya. Serkiz, Funct. Mater. 16(4) (2009) 448-455.

[12] G.S. Zakharova, V.I. Volkov, V.V. Ivanovskaya, A.I. Ivanovskii, Usp. Khim. 74(7) (2005) 651-685.

[13] O.P. Vinogradova, A.I. Sidorov, V.A. Klimov, E.B Shadrin, A.V. Nashchekin, S.D. Khanin, V.Yu. Lyubimov, Phys. Solid State 50(7) (2008) 1227-1231.

[14] A. Dhayal Raj, T. Pazhanivel, P. Suresh Kumar, D. Mangalaraj, D. Nataraj, N. Ponpandian, Current Applied Physics 10 (2010) 531-537.

Proceeding of the XVI International Seminar on Physics and Chemistry of Solids, Lviv, June 6-9, 2010. 